Article

\title{
Experimental Study of Sulfonate Gemini Surfactants as Thickeners for Clean Fracturing Fluids
}

\author{
Shanfa Tang ${ }^{1,2}$, Yahui Zheng ${ }^{2, *}$, Weipeng Yang ${ }^{3, * \mathbb{C}}$, Jiaxin Wang ${ }^{2}$, Yingkai Fan ${ }^{2}$ and Jun $\mathrm{Lu}^{3}$ \\ 1 Hubei Cooperative Innovation Center of Unconventional Oil and Gas in Yangtze University, \\ Wuhan 430100, China; tangsf2005@126.com \\ 2 School of Petroleum Engineering, Yangtze University, Wuhan 430100, China; \\ 201672102@yangtzeu.edu.cn (J.W.); 201772084@yangtzeu.edu.cn (Y.F.) \\ 3 McDougall School of Petroleum Engineering, The University of Tulsa, Tulsa, OK 74104, USA; \\ jun-lu@utulsa.edu \\ * Correspondence: 201671182@yangtzeu.edu.cn (Y.Z.); weipeng-yang@utulsa.edu (W.Y.); \\ Tel.: +86-130-2710-8092 (Y.Z.); +1-918-964-2735 (W.Y.)
}

Received: 24 October 2018; Accepted: 13 November 2018; Published: 16 November 2018

\begin{abstract}
Hydraulic fracturing is one of the important methods to improve oil and gas production. The performance of the fracturing fluid directly affects the success of hydraulic fracturing. The traditional cross-linked polymer fracturing fluid can cause secondary damage to oil and gas reservoirs due to the poor flow-back of the fracturing fluid, and existing conventional cleaning fracturing fluids have poor performance in high temperature. Therefore, this paper has carried out research on novel sulfonate Gemini surfactant cleaning fracturing fluids. The rheological properties of a series of sulfonate Gemini surfactant (DSm-s-m) solutions at different temperatures and constant shear rate $\left(170 \mathrm{~s}^{-1}\right)$ were tested for optimizing the temperature-resistance and thickening properties of anionic Gemini surfactants in clean fracturing fluid. At the same time, the microstructures of solutions were investigated by scanning electron microscope (SEM). The experimental results showed that the viscosity of the sulfonate Gemini surfactant solution varied with the spacer group and the hydrophobic chain at $65{ }^{\circ} \mathrm{C}$ and $170 \mathrm{~s}^{-1}$, wherein DS18-3-18 had excellent viscosity-increasing properties. Furthermore, the microstructure of $4 \mathrm{wt} . \%$ DS18-3-18 solution demonstrated that DS18-3-18 self-assembled into dense layered micelles, and the micelles intertwined with each other to form the network structure, promoting the increase in solution viscosity. Adding nano- $\mathrm{MgO}$ can increase the temperature-resistance of $4 \mathrm{wt} . \%$ DS18-3-18 solution, which indicated that the rod-like and close-packed layered micelles were beneficial to the improvement of the temperature-resistance and thickening performances of the DS18-3-18 solution. DS18-3-18 was not only easy to formulate, but also stable in all aspects. Due to its low molecular weight, the damage to the formation was close to zero and the insoluble residue was almost zero because of the absence of breaker, so it could be used as a thickener for clean fracturing fluids in tight reservoirs.
\end{abstract}

Keywords: sulfonate gemini surfactant; thickener; temperature-resistance; clean fracturing fluid

\section{Introduction}

The weakness of polymer crosslinking fracturing fluid in field applications are becoming more and more obvious with the development of unconventional oil reservoirs [1-5]. Compared with the traditional cross-linked polymer fracturing fluids, clean fracturing fluids consist of a viscoelastic surfactant and a corresponding salt solution. The have the advantages of high flowback, simple on-site preparation, simple injection process and less damage to the formation [6]. As is shown in Table 1, compared with the guanidine gum fracturing fluid, the cleaning fracturing fluid has many significant 
advantages. However, the increase of temperature is not conducive to the formation of closely packed worm-like micelles in solution for the conventional single-chain surfactants, which results in low viscosity and poor thickening performance [7]. Simultaneously, the amount of surfactant will obviously increase with the increase of temperature, and the cost of clean fracturing fluids will increase significantly [8,9]. Gemini surfactants have a special molecular structure including two hydrophilic groups and two hydrophobic chains. They have characteristics of lower oil-water interfacial tension, CMC, Krafft point, and higher viscosity compared with conventional single-chain surfactants [10-12]. Gemini surfactants can form stable micellar structures with obvious thickening effects at low concentration. Therefore, they have broad application potential in constructing a temperature-resistant thickening clean fracturing fluid system $[13,14]$. At present, the application of Gemini surfactants in cleaning fracturing fluids is mainly concentrated on cationic Gemini surfactants [15]. Zhu et al. [16] added $4 \mathrm{wt} . \% \mathrm{NaCl}$ or $15 \mathrm{wt} . \%$ hydrochloric acid to $2-2.5 \mathrm{wt} . \%$ cationic Gemini surfactant solution to form a clean fracturing fluid. The temperature resistance of the mixed solution could be up to $95^{\circ} \mathrm{C}$ and $80^{\circ} \mathrm{C}$, respectively. Yang et al. [17] found that the $1.0 \mathrm{wt} . \%$ cationic Gemini surfactant could maintain a high viscosity $(50 \mathrm{mPa} \cdot \mathrm{s})$ at $120^{\circ} \mathrm{C}$ and $100 \mathrm{~s}^{-1}$. Yu [18] studied the viscosity characteristics and the micellar structures of cationic Gemini surfactants. It was found that by increasing the hydrophobic chain length at $s=2$, the linear micelles in the solution tended to aggregate to form a network structure which led to an increase in viscosity.

Table 1. Comparison of clean fracturing fluid and guanidine gum fracturing fluid.

\begin{tabular}{|c|c|c|}
\hline Parameter & Clean Fracturing Fluid & Guanidine Gum Fracturing Fluid \\
\hline Molecular weight category & Molecular weight less than 500 & Molecular weight greater than 50,000 \\
\hline With or without crosslinker & No & Yes \\
\hline With or without a breaker & No & Yes \\
\hline Sand carrying mechanism & $\begin{array}{l}\text { Viscoelastic body carrying sand, viscosity } \\
\text { greater than } 30 \mathrm{mPa} \cdot \mathrm{s} \text { at } 100 \mathrm{~s}^{-1}\end{array}$ & $\begin{array}{l}\text { Fracturing fluid carrying sand, viscosity } \\
\text { greater than } 100 \mathrm{mPa} \cdot \mathrm{s} \text { at } 100 \mathrm{~s}^{-1}\end{array}$ \\
\hline Filtration loss & Low filtration & High filtration \\
\hline Diversion capacity & More than $93 \%$ & More than $70 \%$ \\
\hline Craftsmanship & Easy to make on site & Difficult to make on site \\
\hline
\end{tabular}

However, because of the positive charge-carrying properties of cationic Gemini surfactants, they are easily adsorbed on the surface of oil-bearing rocks, leading to alteration of the wettability of the oil-gas seepage channels and about $14 \mathrm{wt} . \%$ permeability damage to the reservoir [19]. Due to the fact that anionic Gemini surfactants have a lower adsorption than cationic Gemini surfactants, in recent years, scholars have studied anionic Gemini surfactant viscoelastic fracturing fluids. Several studies have shown that the viscosity of the sulfonate Gemini surfactant solutions is affected by the hydrophobic carbon chain and spacer length and additive concentration [20-22]. Moreover, the viscosity behavior of a sulfonate Gemini surfactant solution was investigated. It was concluded that the viscosity of the $0.6 \mathrm{wt} . \%$ surfactant solution could be $90 \mathrm{mPa} \cdot \mathrm{s}$ at $30{ }^{\circ} \mathrm{C}$ and $6 \mathrm{~s}^{-1}$. However, when the temperature exceeded $60{ }^{\circ} \mathrm{C}$, the viscosity of the solution was close to that of water which indicated that the temperature resistance was poor. Tang et al. [23] formulated a carboxylate Gemini surfactant clean fracturing fluid containing $3 \mathrm{wt} . \%$ DC16-4-16 and $0.04 \mathrm{wt} . \%$ $\mathrm{ZnO}$, and they found that it had high viscosity of $30 \mathrm{mPa} \cdot \mathrm{s}$ at $100{ }^{\circ} \mathrm{C}$. For application of anionic Gemini surfactants as thickeners for clean fracturing fluids, the temperature-thickening properties of the anionic Gemini surfactant solution are particularly important [24]. In addition, studies have shown that spacer group and hydrophobic carbon chain play the most important role in the viscosity of anionic Gemini surfactant solutions [25]. The bisulphonate structure in sulfonate Gemini surfactants makes them have good water solubility, coupling and high surface activity, and their raw material sources are relatively extensive, and the synthesis method is relatively simple, so sulfonate Gemini surfactants are most likely to achieve large-scale industrial production.

Clean fracturing fluid studies are now mainly focused on the study of cationic viscoelastic surfactants and have been used successfully in some oil fields. However, the cationic surfactant and 
the cationic Gemini surfactant cleaning fracturing fluid easily cause reservoir damage, and have the problems of poor degradability and pollution damage to the environment and increased consumption cost at high temperature. Simultaneously, the newly developed conventional anionic Gemini surfactant cleaning fracturing fluids have problems of high dosage of chemicals and poor high temperature stability. Therefore, a systematic investigation of the effects of hydrophobic carbon chain, spacer group, temperature, concentration, and additives on the viscosity of novel sulfonate Gemini surfactants is needed. Constructing a new non-invasive and temperature-resistant clean fracturing fluid to solve the problems of high dosage, poor temperature stability and inability to automatically break of the existing clean fracturing fluid has obvious scientific significance and practical value. The results have scientific, social and economic value for the efficient development of oil and gas reservoirs.

In this paper, the effects of hydrophobic chain, spacer group, concentration, temperature and addition of nano-MgO on the viscosity of sulfonate Gemini surfactant solution were investigated by measuring the solution viscosity. Then, their micellar microstructures were observed by Cryo-SEM. Finally, the thickening mechanism of sulfonate Gemini surfactant was investigated by correlating the relationship between solution viscosity and its microstructure. Therefore, this research studied the rheological properties of the sulfonate Gemini surfactant solution and provided experimental basis for the application of sulfonate Gemini surfactants in clean fracturing fluid.

\section{Materials and Methods}

The sulfonate Gemini surfactants shown in Table 2 were purified twice. By accurately weighing $4 \mathrm{~g}$ of each surfactant and dissolving in distilled water in a $50 \mathrm{~mL}$ volumetric flask, $8.0 \mathrm{wt} . \%$ solutions of different sulfonate Gemini surfactants were prepared. Other surfactant solution concentrations were prepared by appropriately diluting the $8.0 \mathrm{wt} . \%$ solution.

Table 2. Sulfonate Gemini surfactants and their classification.

\begin{tabular}{cc}
\hline Spacer & Sulfonate Gemini Surfactant (DSm-s-m) \\
\hline $\mathrm{s}=2$ & DS12-2-12, DS14-2-14, DS16-2-16, DS18-2-18 \\
$\mathrm{s}=3$ & DS18-3-18 \\
$\mathrm{s}=4$ & DS18-4-18 \\
\hline $\mathrm{m}$ : hydrophobic chain carbon number, s: spacer group carbon number.
\end{tabular}

By accurately weighing $0.4 \mathrm{~g}$ of nano-MgO and dissolving in distilled water in a $100 \mathrm{~mL}$ volumetric flask, a $0.4 \mathrm{wt} . \%$ solution of nano- $\mathrm{MgO}$ was prepared. Other solution concentrations were prepared by diluting the $0.4 \mathrm{wt} . \%$ solution.

Viscosity tests of sulfonate Gemini surfactant solutions were performed using a MCR-301 rheometer (Anton-Paar, Graz, Austria). The temperature for analysis ranged from 50 to $90{ }^{\circ} \mathrm{C}$ (the experimental temperature was $65^{\circ} \mathrm{C}$ if no special instructions are given), and the shear rate was fixed with $170 \mathrm{~s}^{-1}$ according to the Oil and Gas Industry Standard SY/T5107-2005. The viscosity data in the figures below were all averaged after three times unless otherwise stated, and the viscosity test error was $1 \mathrm{mPa} \cdot \mathrm{s} \pm 0.005 \mathrm{mPa} \cdot \mathrm{s}$.

The micellar structure of sulfonate Gemini surfactant solution was observed using a S4800 FESEM (Hitachi, Toyko, Japan). The test solution was placed in a liquid nitrogen tank for quick freezing. After freezing, the sample was quickly placed in a freeze dryer for $24 \mathrm{~h}$. The sample was coated with a conductive plastic on a scanning electron microscope, and the sample was sprayed using ion sputtering apparatus. Finally, the sample was observed by the $\$ 4800$ field emission scanning electron microscope.

This experimental method can directly link the macroscopic solution viscosity to the microstructure, and then the effect of the micelle on the viscosity of the solution can be investigated, which is beneficial to the study of the thickening mechanism. 
The disadvantage of this experimental method is that the scanning electron microscope can only qualitatively observe the microstructure of the solution micelles but cannot quantitatively describe the size and diameter of the micelles.

\section{Results and Discussion}

\subsection{Effect of Hydrophobic Chain on the Viscosity of Sulfonate Gemini Surfactant Solution}

The effect of hydrophobic chain on the viscosity of sulfonate Gemini surfactant (DS-m-2-m) solution $(8.0 \mathrm{wt} . \%)$ was studied at $65{ }^{\circ} \mathrm{C}$ and $170 \mathrm{~s}^{-1}$. As can be seen from Figure 1, the viscosity of sulfonate Gemini surfactant solution increases with increasing carbon number of the hydrophobic chain. The reason for this phenomenon is the hydrophobicity of the molecule increases as the length of the hydrophobic chain increases, which promotes the formation of micelles in the solution, and the micelles become tightly entangled with each other, leading to the increase in solution viscosity [26]. The DS-16-2-16 solution's viscosity is slightly lower, probably because the long hydrophobic chain is easily deformed, making for less effective hydrophobic groups in the solution and a decrease of solution viscosity [27]. To better explain this phenomenon, the micellar structures for selected sulfonate Gemini surfactant solution are shown in Figure 2. DS-12-2-12 in solution self-assembles to form distinct spherical micelles with a diameter of about $200 \mathrm{~nm}$. The spherical micelles are closely arranged forming a plate shape. DS-14-2-14 in solution self-assembles into rod micelles. Even though the diameters of rod micelles are about $100 \mathrm{~nm}$, these micelles are tightly packed together. In addition, DS-16-2-16 self-assembles into spherical and rod-shaped micelles, and their diameters are about 100 to $200 \mathrm{~nm}$. More importantly, these micelles are packed closer than in DS12-2-12. DS-18-2-18 also self-assembles in solution to form spherical and ellipsoid (like rods) micelles, but their diameters are approximately $300 \mathrm{~nm}$. Unlike DS12-2-12 and DS16-2-16, these micelles are loosely arranged, and only a few micelles form the network structure. Therefore, DS-18-2-18 has a better viscosity-increasing effect, and the maximum viscosity of the micelle solution is $14.7 \mathrm{mPa} \cdot \mathrm{s}$.

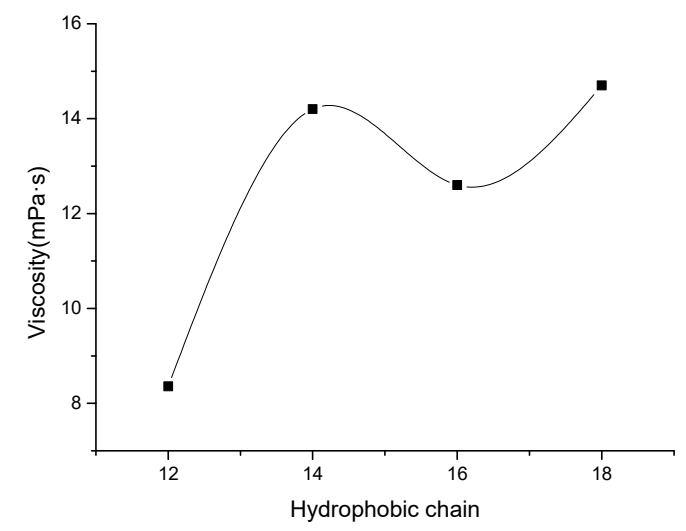

Figure 1. Effect of hydrophobic chain on the viscosity of DSm-2-m solution.

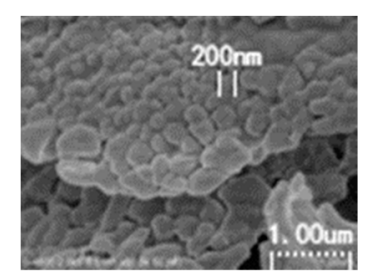

(a) DS12-2-12

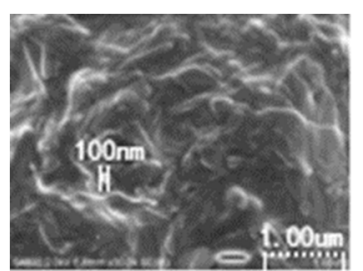

(b) DS14-2-14

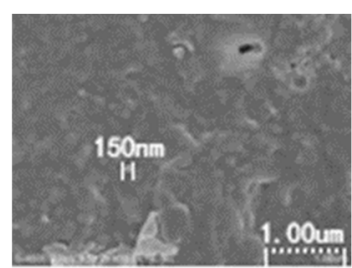

(c) DS16-2-16

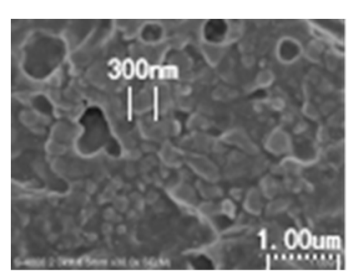

(d) DS18-2-18

Figure 2. Effect of hydrophobic chain on micelle structure of DSm-2-m solution. 


\subsection{Effect of Spacer Group on the Viscosity of Sulfonate Gemini Surfactant Solution}

The effect of spacer group on the viscosity of sulfonate Gemini surfactant (DS-18-s-18) solution (8.0 wt.\%) was studied at $65{ }^{\circ} \mathrm{C}$ and $170 \mathrm{~s}^{-1}$. It can be seen from Figure 3 that the viscosity of the sulfonate Gemini surfactant solution increases dramatically when the spacer group carbon number increases from 2 to 3, and the solution viscosity reaches a maximum of $56.53 \mathrm{mPa} \cdot \mathrm{s}$. The viscosity decreases after the spacer group carbon number increases to 4 . Figure 4 shows the micelle structures of the selected sulfonate Gemini surfactants. DS-18-2-18 self-assembles in solution to form spherical and ellipsoid (like rods) micelles, and their diameter are approximately $300 \mathrm{~nm}$. These micelles are loosely arranged, and only a few micelles form the network structure. DS-18-3-18 self-assembles in solution to form layered micelles, which are intertwined to form a similar network structure. In addition, DS-18-4-18 self-assembles into a flat-shaped structure with spherical micelles, but these micelle structures are loosely arranged and cannot fill the whole space. Thus, as the spacer group changes, the microstructures of selected DS18-s-18 solution undergoes a transition from spherical micelles to a network of layered micelles and finally to spherical/layered mixed micelles. DS-18-3-18 has a better thickening behavior under the experimental conditions.

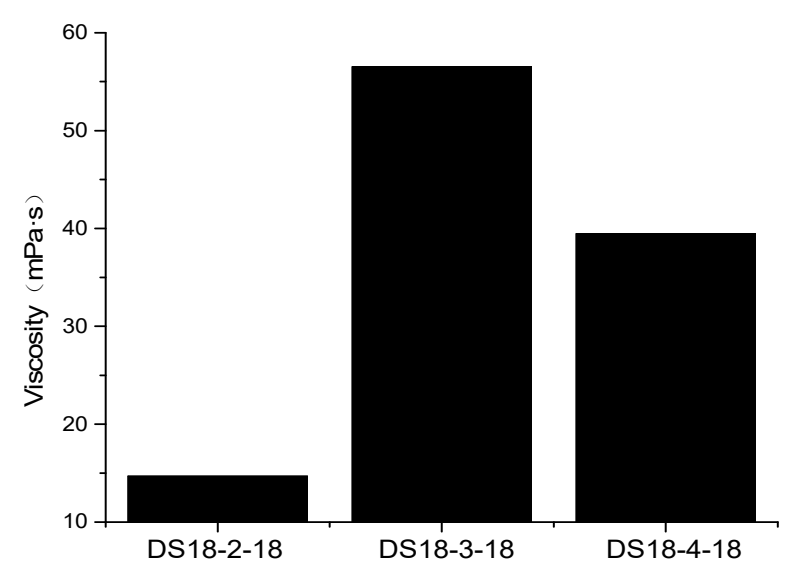

Figure 3. Effect of spacer group on the viscosity of DS18-s-18 solution(s = 2, 3, 4).

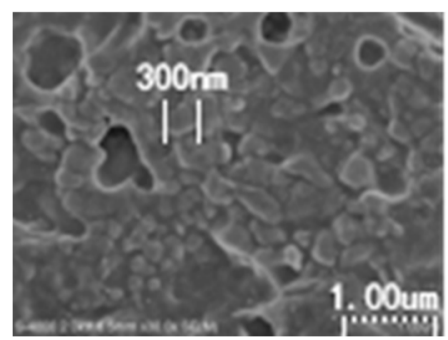

(a) DS18-2-18

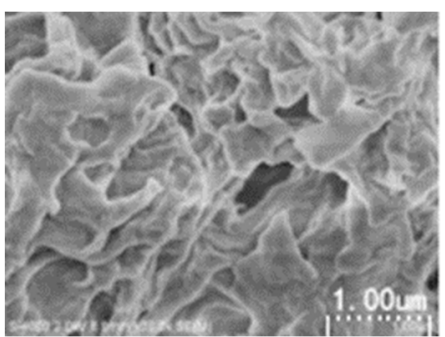

(b) DS18-3-18

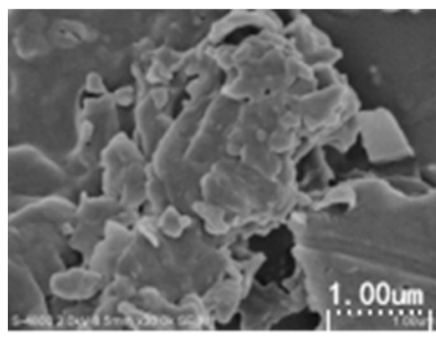

(c) DS18-4-18

Figure 4. Effect of spacer group on micelle structure of DS18-s-18 solution(s $=2,3,4)$.

\subsection{Effect of Concentration on the Viscosity of DS18-3-18 Solution}

According to the results in Sections 3.1 and 3.2, DS18-3-18 was selected as thickener for our clean fracturing fluid. The effect of concentration on DS-18-3-18 solution viscosity was studied at $65{ }^{\circ} \mathrm{C}$ and $170 \mathrm{~s}^{-1}$. It can be observed from Figure 5 that the solution viscosity increases with the concentration, and the viscosity increases sharply when concentration increases from $3.0 \mathrm{wt} . \%$ to $4.0 \mathrm{wt} . \%$. When the solution concentration is higher than $4.0 \mathrm{wt} . \%$, the increase tendency of the viscosity becomes slower, and the thickening ability becomes weak. The reason for this phenomenon is that the sulfonate Gemini surfactant will form the dense network structure in solution with increasing concentration, which is beneficial to the increase of solution viscosity. However, with the increase of concentration, the micelle structure ultimately reaches a stable state, resulting in little change in 
viscosity [28]. The effect of concentration on microstructure of DS18-3-18 was investigated, and the results are exhibited in Figure 6. DS18-3-18 self-assembles into incomplete sheet micelles, and these micelles can't cover the whole space when the concentration is $1.0 \mathrm{wt} . \%$. Then the complete sheet structures appeared in the DS18-3-18 solution and occupy the entire space when the concentration was $2.0 \mathrm{wt} . \%$ (Figure $6 \mathrm{~b}$ ). The number of sheet micelles increased, and some of the sheet micelles aggregated to form closely-coupled rod micelles, forming a network structure, and the density of the micelles in the solution became greater when the concentration was $4.0 \mathrm{wt}$.\% (Figure 6c). It can be seen that the micelle structure gradually changed from an incomplete sheet micelle to tightly wound rod-like and sheet structures as the concentration increased. Thus, $4.0 \mathrm{wt} . \%$ DS-18-3-18 was selected as thickener's concentration for the next research of thickening effect.

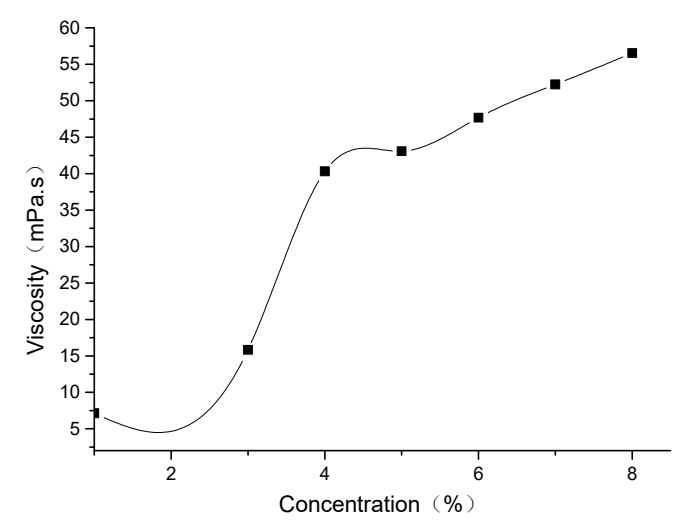

Figure 5. Effect of concentration on the viscosity of DS18-3-18.

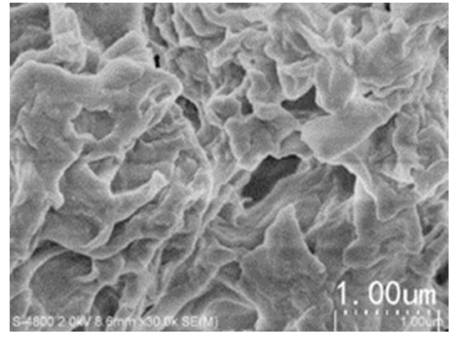

(a) 1.0 wt.\% DS18-3-18

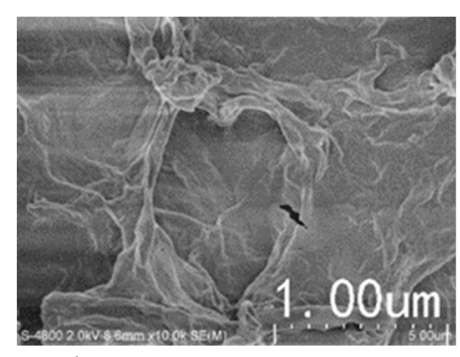

(b) 2.0 wt.\% DS18-3-18

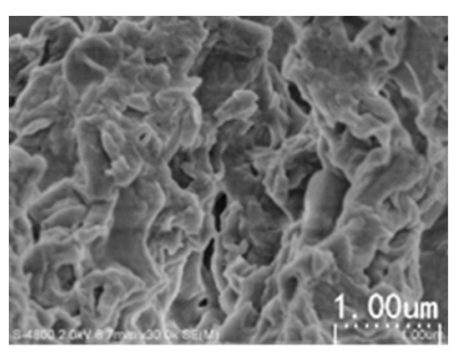

(c) 4.0 wt.\% DS18-3-18

Figure 6. Effect of concentration on micelle structure of DS18-3-18.

\subsection{Effect of Temperature on Viscosity of DS18-3-18 Solution}

The relationship between DS-18-3-18 solution viscosity and temperature was studied, and the results are shown in Figure 7. As the temperature increases, the solution viscosity of $4.0 \mathrm{wt} . \%$ DS18-3-18 shows a downward trend. In particular, there is a significant decrease in DS18-3-18 solution viscosity when temperature increases from $60{ }^{\circ} \mathrm{C}$ to $70^{\circ} \mathrm{C}$. Then the tendency slows down when the temperature exceeds $70{ }^{\circ} \mathrm{C}$. This is because the network micelles in DS18-3-18 solution will be destroyed as temperature increases [29,30]. Moreover, lamellar micelles, reticular micelles, and worm-like micelles can help to keep the viscosity stability of DS18-3-18 solution at higher temperatures. To further investigate the mechanism of temperature-resistance thickening of DS18-3-18 solution, the self-assembly morphology of DS18-3-18 micelles were characterized by scanning electron microscopy, and the electronic micrographs are shown in Figure 8, where it can be seen that DS18-3-18 self-assembles into a complete layered micelle, and the layered micelles have large pieces of sheet micelles attached at $50{ }^{\circ} \mathrm{C}$. When the temperature raised to $70{ }^{\circ} \mathrm{C}$, the lamellar micelles gradually disintegrate to form sheet micelles, and these sheet micelles became smaller (Figure $8 \mathbf{b}$ ). Then the sheet micelle structures in the solution became sparse, and part of the sheet structure disintegrated to form 
irregular spherical micelles and rod-like micelles at $90^{\circ} \mathrm{C}$. But these micelles still formed the network structure in solution (Figure 8c).

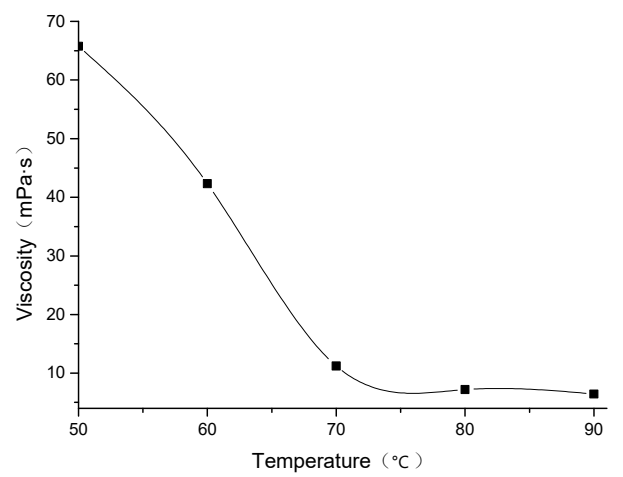

Figure 7. Effect of temperature on the viscosity of 4 wt.\% DS18-3-18.

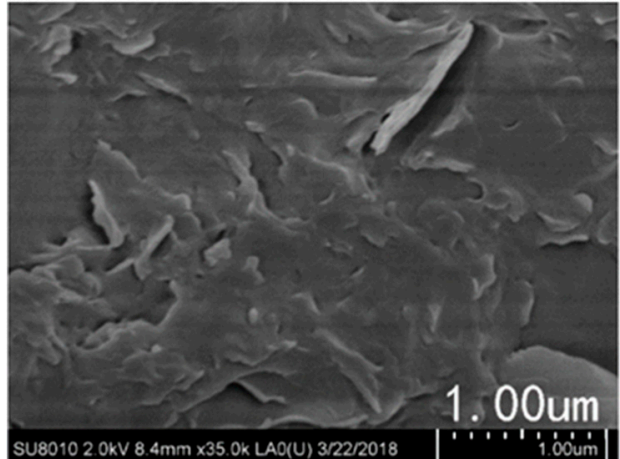

(a) $50{ }^{\circ} \mathrm{C}$ DS18-3-18 solution structure

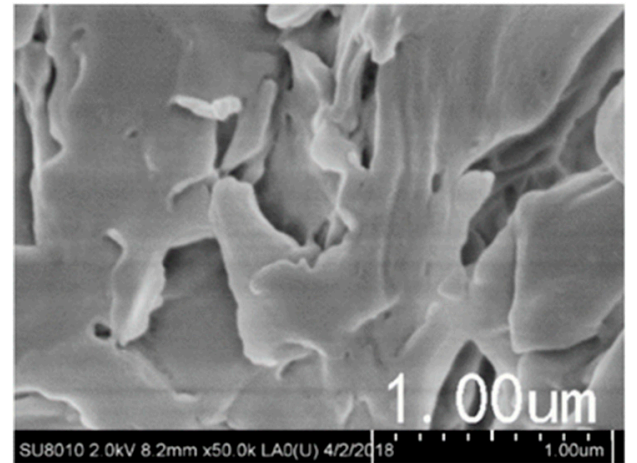

(b) $70{ }^{\circ} \mathrm{C}$ DS18-3-18 solution structure

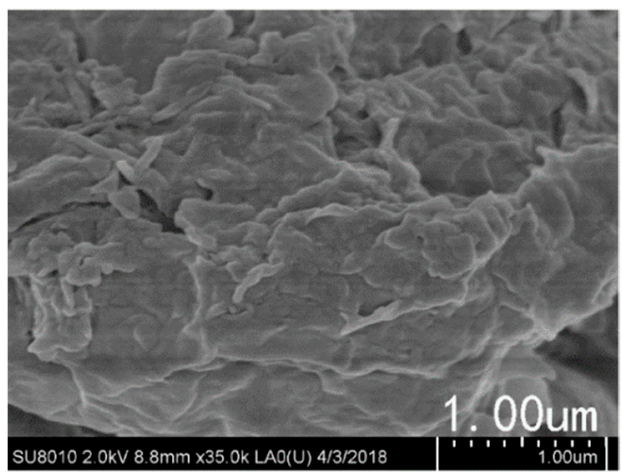

(c) $90{ }^{\circ} \mathrm{C}$ DS18-3-18 solution structure

Figure 8. Effect of temperature on the micelle structure of $4.0 \mathrm{wt.} \%$ DS18-3-18.

This indicates that the density of network lamellar micelles in DS18-3-18 solution decreases as the temperature increase, and the morphology of the micelles gradually becomes incomplete, resulting in a decrease in solution viscosity. But the spatial network structure is conducive to the DS18-3-18 solution viscosity when temperature is higher than $70^{\circ} \mathrm{C}$. Thus, DS18-3-18 solution viscosity was still $6.42 \mathrm{mPa} \cdot \mathrm{s}$ at $90^{\circ} \mathrm{C}$, which exhibited prominent thickening ability and tolerance of DS18-3-18 at high temperature $\left(>80^{\circ} \mathrm{C}\right)$. 


\subsection{Effect of Nano-MgO on the Viscosity of $4.0 \mathrm{wt} . \%$ DS18-3-18}

The influences of nano-MgO concentration on the $4.0 \mathrm{wt} . \%$ solution viscosity were studied at $90{ }^{\circ} \mathrm{C}$. Figure 9 shows that the DS18-3-18 solution viscosity increases firstly and then decreases as the nano- $\mathrm{MgO}$ concentration increases at high temperature. When $0.02 \mathrm{wt} \%$ nano- $\mathrm{MgO}$ is added, the solution viscosity reaches its maximum of $21.87 \mathrm{mPa} \cdot \mathrm{s}$, which meet the required viscosity of a clean fracturing fluid. This is because the nano-MgO with extremely high specific surface area and can be easily adsorbed on the micelle end plane or surface in the DS18-3-18 solution when the nano-MgO concentration is low. Therefore, nano-MgO particles shield the micelles from electrostatic repulsion, which is beneficial to form the network micelles and increase solution viscosity [31]. Due to the high content (4.0 wt.\%) of DS18-3-18, double-layered structures were formed with the nano-MgO through non-covalent bonds. The hydrophilic heads of the surfactants faced outward, and the nanoparticles were in the center [32]. As the mass fraction of nano-MgO continued to increase, it was more conducive to the formation of this double-layer structure, which promoted the repulsion between DS18-3-18 solution micelles and weakened the stability of the network structure. Therefore, the viscosity and temperature-resistance of the solution were reduced when the nano-MgO reached a certain mass fraction. To better explain the observed phenomena, the micellar structures of the DS18-3-18 solution with different concentration of nano- $\mathrm{MgO}$ were investigated. As can be seen from Figure 10, $4.0 \mathrm{wt} . \%$ DS18-3-18 self-assembles into sparse sheet micelles. Then the aggregated rod-like micelle structure appears on the sheet-like micelle structure in solution when adding $0.01 \mathrm{wt} . \%$ nano-MgO. The rod-like micelles accumulated through the structure of the sheet micelles in the DS18-3-18 solution gradually became larger and aggregated into a compact layer when the concentration of nano-MgO was $0.02 \mathrm{wt} . \%$ (Figure 10c). Finally, the compact layer structure gradually became sparse, and the rod-like micelles gradually transformed into worm-like micelle structure when the concentration was $0.03 \mathrm{wt} . \%$ (Figure 10d). Also, the viscosity of DS18-3-18 solution firstly increases and then decreases with the increase of nano-MgO concentration. Therefore, nano-MgO affect viscosity of $4.0 \mathrm{wt} . \%$ DS18-3-18 solution in high temperature though changing micellar structure morphology of DS18-3-18 solution, and it has the best temperature-resistant thickening effect on solution viscosity at the concentration of $0.02 \mathrm{wt} . \%$.

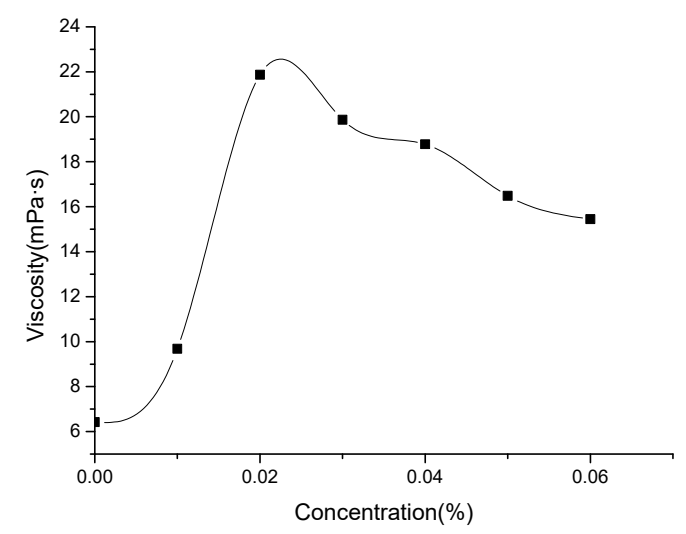

Figure 9. Effect of nano-MgO concentration on the viscosity of 4.0 wt.\% DS18-3-18. 


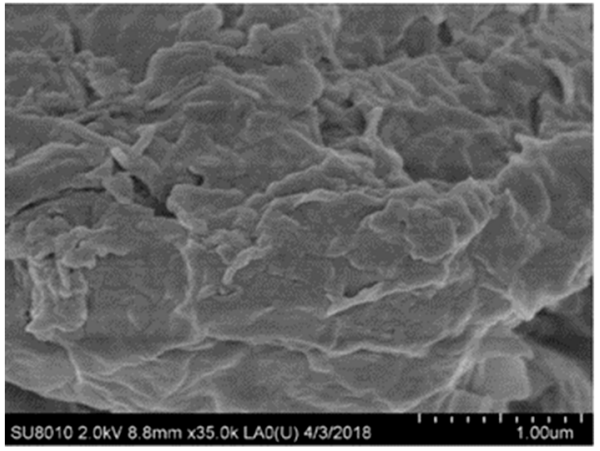

(a) 4.0 wt. $\%$ DS18-3-18

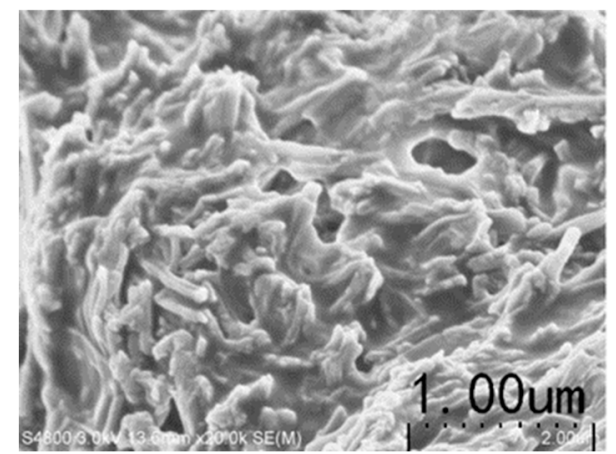

(c) 4.0 wt. $\%$ DS18-3-18 + 0.02 wt. \% nano-MgO

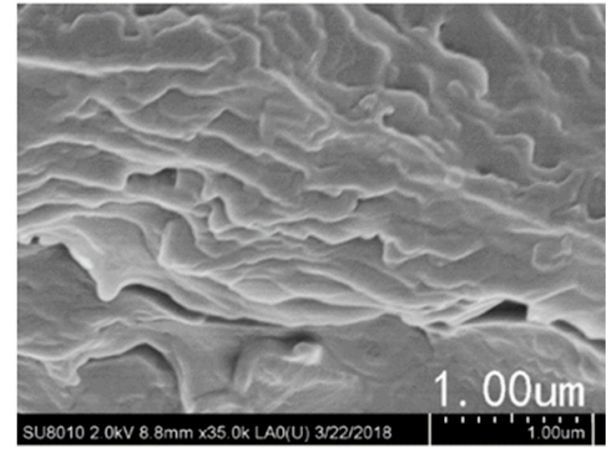

(b) 4 wt.\% DS18-3-18+0.01 wt.\% nano-MgO

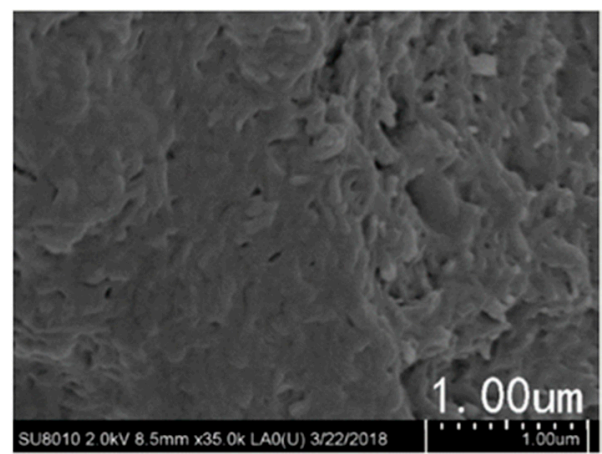

(d) 4.0 wt. \% DS18-3-18 + 0.03 wt. \% nano-MgO

Figure 10. Effect of different concentration of nano-MgO on the micelle structure of DS18-3-18 solution.

\section{Conclusions}

The effects of molecular structure, temperature and addition of nano-MgO on the viscosity of sulfonate Gemini surfactants were investigated by testing the solution viscosity. The micelles of the solution were observed by Cryo-SEM, and the mechanism of increasing the viscosity in surfactant solution was explored. The most important conclusions for this work are summarized as below:

(1) The viscosity of the DSm-s-m solution showed a fluctuating upward trend with increasing the length of hydrophobic chain at $\mathrm{s}=2$. Meanwhile, the viscosity of the DS18-s-18 solution increased firstly and decreased later with increasing spacer group length. Moreover, DS18-3-18 showed prominent viscosity behavior.

(2) The viscosity of the DS18-3-18 solution increased as the increase of surfactant concentration, and the tendency of the increase became slow when the solution concentration exceeded $4.0 \mathrm{wt} . \%$.

(3) $4.0 \mathrm{wt} . \%$ DS18-3-18 solution had better temperature-resistance, and the viscosity of the solution kept above $6 \mathrm{mPa} \cdot \mathrm{s}$ at $90^{\circ} \mathrm{C}$ and $170 \mathrm{~s}^{-1}$, which satisfied the experimental requirements for a clean fracturing fluid thickener.

(4) The addition of nano-MgO improved the temperature-resistance of $4.0 \mathrm{wt} . \%$ DS18-3-18 solution. The viscosity of the solution increased firstly and decreased later with increasing nano-MgO concentration. The viscosity of the solution reached its maximum of $21.87 \mathrm{mPa} \cdot \mathrm{s}$ at $90{ }^{\circ} \mathrm{C}$ when $0.02 \mathrm{wt} . \%$ nano-MgO was added, which achieved the required viscosity of the clean fracturing fluid.

(5) DS18-3-18 self-assembled intodense layered micelles, and the micelles entangled with each other to form a network structure, contributing to the better temperature-resistance and higher viscosity. Nano-MgO further enhanced the temperature-resistance of $4.0 \mathrm{wt} . \%$ DS18-3-18 solution by changing the micellar morphology.

(6) The limitation of this experimental study was that the temperature resistance of the sulfonate Gemini surfactant can only reach $90^{\circ} \mathrm{C}$, and the cost was slightly higher. 
(7) Compared with other studies, DS18-3-18 had a temperature resistance of $90^{\circ} \mathrm{C}$, and the viscosity after adding nano-MgO could reach up to $21.87 \mathrm{mPa} \cdot \mathrm{s}$, which meet the viscosity requirements of a clean fracturing fluid and has good application prospects.

Author Contributions: S.T. and Y.Z., designed the experimental framework and wrote the paper. J.W. and Y.F. conducted experiments and collected datas. W.Y. and J.L. checked and revised the paper.

Funding: This work is funded by the National Natural Science Foundation of China $(51474035,51774049)$ and Innovation Fund Project of Hubei Cooperative Innovation Center of Unconventional Oil and Gas (HBUOG-2014-2).

Conflicts of Interest: The authors declare no conflicts of interest.

\section{References}

1. Zhang, L.; Kou, Z.; Wang, H.; Zhao, Y.; Dejam, M.; Guo, J.; Du, J. Performance analysis for a model of a multi-wing hydraulically fractured vertical well in a coalbed methane gas reservoir. J. Pet. Sci. Eng. 2018, 166, 104-120. [CrossRef]

2. Dejam, M.; Hassanzadeh, H.; Chen, Z. Semi-analytical solution for pressure transient analysis of a hydraulically fractured vertical well in a bounded dual-porosity reservoir. J. Hydrol. 2018, 565, 289-301. [CrossRef]

3. Seright, R.S. How Much Polymer Should Be Injected During a Polymer Flood? In Proceedings of the SPE Improved Oil Recovery Conference, Tulsa, OK, USA, 11-13 April 2016.

4. Saboorian-Jooybari, H.; Dejam, M.; Chen, Z. Heavy oil polymer flooding from laboratory core floods to pilot tests and field applications: Half-century studies. J. Pet. Sci. Eng. 2016, 142, 85-100. [CrossRef]

5. Rui, Z.; Wang, X.; Zhang, Z.; Lu, J.; Chen, G.; Zhou, X.; Patil, S. A realistic and integrated model for evaluating oil sands development with Steam Assisted Gravity Drainage technology in Canada. Appl. Energy 2018, 213, 76-91. [CrossRef]

6. Yan, Z.; Dai, C.; Zhao, M.; Feng, H.; Gao, B.; Li, M. Research and Application Progress of Cleaning Fracturing Fluid. Oilfield Chem. 2015, 32, 141-145.

7. Yan, Z.; Dai, C.; Zhao, M.; Sun, Y. Rheological characterizations and molecular dynamics simulations of self-assembly in an anionic/cationic surfactant mixture. Soft Matter 2016, 12, 6058-6066. [CrossRef] [PubMed]

8. Yan, J.; Wang, F. Wettability alteration of silica induced by surfactant adsorption. Oilfield Chem. 1993, 10, 195-200.

9. Zhang, J.; Zhang, M.; Zhang, S.; Bai, B.; Gao, B. Development and Field Pilot Test of a Novel Viscoelastic Anionic-Surfactant Fracturing Fluid. In Proceedings of the Society of Petroleum Engineers Western North American Regional Meeting-In Collaboration with the Joint Meetings of the Pacific Section AAPG and Cordlleran Section GSA, Anaheim, CA, USA, 27-29 May 2010.

10. Lai, L.; Mei, P.; Wu, X.; Hou, C.; Zheng, Y.; Liu, Y. Micellization of anionic gemini surfactants and their interaction with polyacrylamide. Colloid Polym. Sci. 2014, 292, 2821-2830. [CrossRef]

11. Pei, X.; Zhao, J.; Ye, Y.; You, Y.; Wei, X. Wormlike micelles and gels reinforced by hydrogen bonding in aqueous cationic gemini surfactant systems. Soft Matter 2011, 7, 2953-2960. [CrossRef]

12. Zana, R. Dimeric and oligomeric surfactants. Behavior at interfaces and in aqueous solution: A review. Adv. Colloid Interface Sci. 2002, 97, 205-253. [CrossRef]

13. Li, G.; Zhao, L.; Wang, P.; Ning, X.; Qin, P.; Xue, M. Synthesis and Surface Activity of Cationic Gemini Surfactant, N,N'-bis(Octadecyl/tetradecyl dimethyl)-1,2-dichloro-1,4-benzene Dimethyl Ammonium Salt. Fine Chem. 2016, 33, 519-523.

14. Tang, S.; Cui, Y.; Xiong, X.; Lei, X. Viscosity and Influencing Factors of Anionic Gemini Surfactant (GA-16) Solution. J. Oil Gas Technol. 2014, 36, 146-149. (In Chinese)

15. Akbas, H.; Elemenli, A.; Boz, M. Aggregation and Thermodynamic Properties of Some Cationic Gemini Surfactants. J. Surfactants Deterg. 2012, 15, 33-40. [CrossRef]

16. Zhu, H.; Niu, H.; Lou, P.; Ding, H.; Zhang, H. Synthesis and Performance of Gemini Surfactant—Containing Acidic Clean Fracturing Fluid. Adv. Fine Petrochem. 2011, 12, 5-8.

17. Yang, J.; Guan, B.; Lu, Y. Viscoelastic Evaluation of Gemini Surfactant Gel for Hydraulic Fracturing. In Proceedings of the SPE European Formation Damage Conference and Exhibition, Noordwijk, The Netherlands, 5-7 June 2013. 
18. Yu, H.; Shen, Y.; Yang, X.; Liu, G.; Zhang, L. Interfacial activity and rheological behavior of N,N'-bis (hexadecyldimethyl)-1,2-dibro-mide-ethanediyl ammonium salt. Acta Pet. Sin. 2014, 30, 542-547.

19. Liu, Y.; Guo, L.; Bi, K.; Ren, W.; Liu, L.; Li, Y.; Han, L. Synthesis of Cationic Gemini Surfactant and Its Application in Water Blocking. Fine Spec. Chem. 2011, 19, 8-10. (In Chinese)

20. Tang, S.; Liu, Z.; Liu, S.; Hu, X.; Wu, R. Research on Rheological Behavior of Anion Gemini Surfactant Solution. Adv. Mater. Res. 2011, 146-147, 536-541. [CrossRef]

21. Pi, Y.; Zhang, L.; Liu, Z.; Gao, D.; Tang, S. Research on Rheological Properties of Sulfuric Acid Ester Salt Gemini Surfactant Solution. J. Oil Gas Technol. 2011, 33, 135-138.

22. Du, X.; Li, L.; Lu, Y.; Yang, Z. Unusual viscosity behavior of a kind of anionic gemini surfactant. Colloid Surf. A 2007, 308, 147-149. [CrossRef]

23. Tang, S.; Zhao, C.; Tian, L.; Zou, T. Temperature-resistance clean fracturing fluid with carboxylate gemini surfactant: A case study of tight sandstone gas reservoirs in the Tarim Basin. Nat. Gas Ind. 2016, 36, 45-51.

24. Mao, J.; Yang, X.; Chen, Y.; Zhang, Z.; Zhang, C.; Yang, B.; Zhao, J. Viscosity reduction mechanism in high temperature of a Gemini viscoelastic surfactant (VES) fracturing fluid and effect of counter-ion salt $(\mathrm{KCl})$ on its heat resistance. J. Pet. Sci Eng. 2018, 164, 189-195. [CrossRef]

25. Zana, R.; Talmon, Y. Dependence of aggregate morphology on structure of dimeric surfactants. Nature 1993, 362, 228-230. [CrossRef]

26. Gao, D.; Yu, M. The Comparative Study of Influence Factors of Ionic Gemini Surfactant Solution's Rheology. J. Chongqing Univ. Sci. Technol. (Nat. Sci. Ed.) 2012, 14, 101-104.

27. Zhu, Q. Study on Synthesis, Properties and Applications in Enhanced Oil Recovery (EOR) of Novel Gemini Surfactant. Master's Thesis, Chengdu University of Technology, Chengdu, China, 2009.

28. Han, L.J.; Chen, H.; Luo, P.Y. Viscosity behavior of cationic gemini surfactants with long alkyl chains. Surf. Sci. 2004, 564, 141-148. [CrossRef]

29. Chen, H.; Ye, Z.; Han, L.; Luo, P.; Zhang, L. Temperature-induced micelle transition of gemini surfactant in aqueous solution. Surf. Sci. 2007, 601, 2147-2151. [CrossRef]

30. Yu, H. Preparation and Performance of Quaternary Ammonium Gemini Surfactant. Master's Thesis, Shaanxi University of Science \& Technology, Xi'an, China, 2010.

31. Yang, J. Study on the Turbulent Flow and Heat Transfer Characteristics of Viscoelastic Fluid Based Nanofluid. Master's Thesis, Harbin Institute of Technology, Harbin, China, 2013.

32. Helgeson, M.E.; Hodgdon, T.K.; Kaler, E.W.; Wagner, N.J.; Vethamuthu, M.; Ananthapadmanabhan, K.P. Formation and Rheology of Viscoelastic “Double Networks" in Wormlike Micelle-Nanoparticle Mixtures. Langmuir 2010, 26, 8049-8060. [CrossRef] [PubMed] 